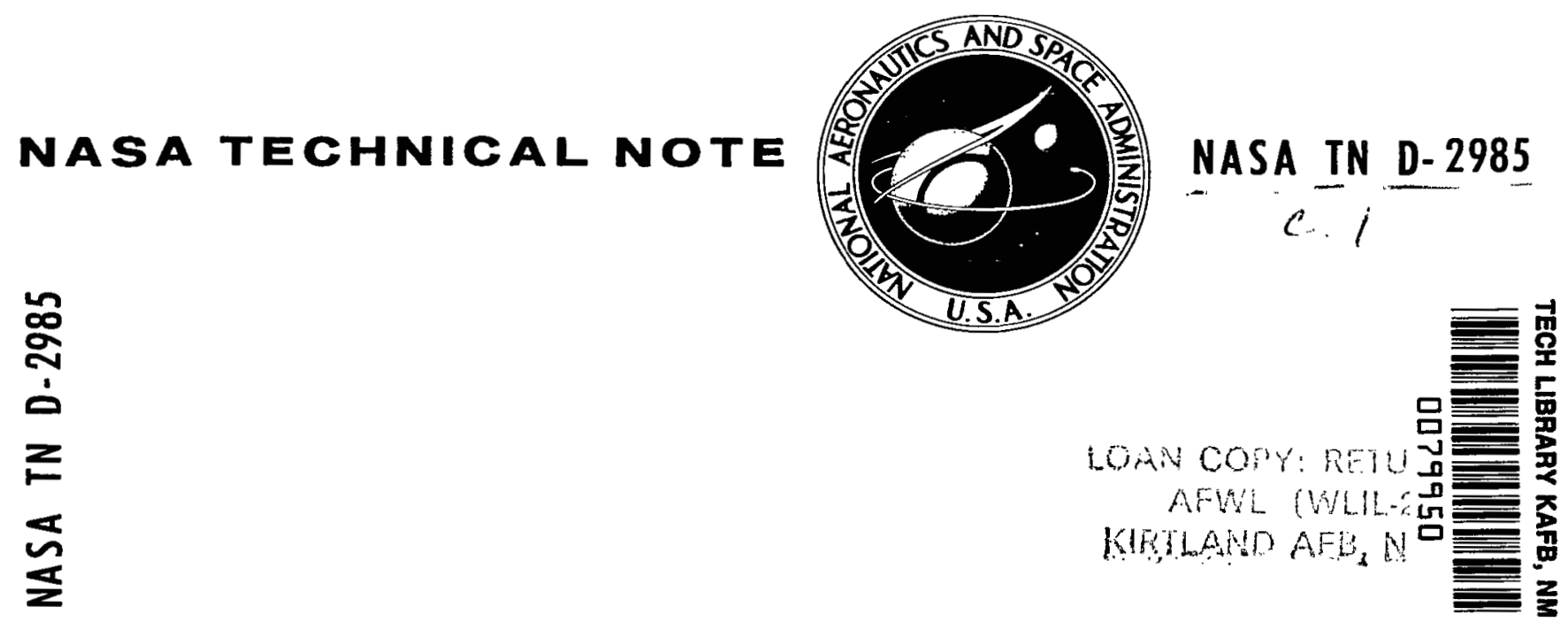

INFLUENCE OF ORDER-DISORDER

TRANSFORMATION ON

FRICTION CHARACTERISTICS OF

COPPER-GOLD ALLOYS IN VACUUM

by Donald H. Buckley

Lewis Research Center

Cleveland, Obio

national aeronautics and SPACE AdMINISTRATION - WASHINGTON, D. C. - SEPTEMber 1965 
INFLUENCE OF ORDER-DISORDER TRANSFORMATION ON FRICTION CHARACTERISTICS OF COPPER-GOLD ALLOYS IN VACUUM

By Donald H. Buckley

Lewis Research Center

Cleveland, Ohio 


\title{
INFLUENCE OF ORDER-DISORDER TRANSFORMATION ON FRICTION CHARACTERISTICS OF COPPER-GOLD ALLOYS IN VACUUM
}

\author{
by Donald $\mathrm{H}$. Buckley
}

\author{
Lewis Research Center
}

\section{SUMMARY}

The influence of order and the order-disorder transformation for copper-gold alloys on friction was determined in vacuum. The copper-gold alloys contained 10, 25, or 50 atomic percent gold. The latter two alloys are the compounds $\mathrm{Cu}_{3} \mathrm{Au}$ and $\mathrm{CuAu}$. Both $\mathrm{Cu}_{3} \mathrm{Au}$ and $\mathrm{CuAu}$ exhibit ordering, while the 10 atomic percent gold in copper does not. Friction experiments were conducted in vacuum $\left(10^{-9} \mathrm{~mm} \mathrm{Hg}\right)$ with a hemispherical rider specimen of the copper-gold alloy sliding on itself or 440-C stainless steel. The specimens were examined under loads of 1000 grams, sliding speeds to 880 centimeters per second, and temperatures to $400^{\circ} \mathrm{C}$.

The results of these studies indicate lower coefficients of friction for the alloys $\mathrm{Cu}_{3} \mathrm{Au}$ and $\mathrm{CuAu}$ in the atomically ordered state than for these alloys in a disordered state. The 10-atomic-percent-gold alloy, which does not become ordered, did not reflect any marked changes in friction when examined under conditions similar to those for $\mathrm{Cu}_{3} \mathrm{Au}$ and $\mathrm{CuAu}$.

\section{INTRODUCTION}

Many mechanical properties influence the friction and adhesion characteristics of metals in a vacuum environment. These mechanical properties can be related to more fundamental factors such as crystal structure. For example, most pure cubic metals such as iron, nickel, and copper will exhibit extremely high friction coefficients and complete welding in vacuum, once surface contaminants are removed (refs. 1 to 3 ). This is also true of many engineering alloys based on such metals (refs. 4 and 5). It has also been shown that low friction and adhesion are obtained for hexagonal metals in adhesion studies (ref. 6) and in vacuum friction studies (refs. 7 and 8). In the friction studies of references 7 and 8 , no evidence was found for mass welding of hexagonal metals. Fric- 
tion and adhesion are believed to reflect the influence of crystalline slip for the various metals. The cubic metals exhibit multiple slip, while the hexagonal metals with nearly ideal close packing exhibit slip on a single plane. Titanium is a special case of the hexagonal metals and is discussed in reference 9. Other factors which may influence the friction behavior of metals are grain size, ordering in metal alloys, stacking fault energies, lattice parameters (atomic density), and ultimately the cohesive energy of metalmetal bonding.

One of the factors which exhibits a marked influence on the behavior of some metal systems is ordering, which will be graphically described in the section ORDER-DISORDER TRANSFORMATION. Properties of metals such as elastic modulus, shear strength, electrical resistivity, and hardness can be markedly influenced by order-disorder transformations (refs. 10 and 11). There are many metal compounds which exhibit ordering or are classified as superlattice alloys. Such systems as copper-gold, copper-zinc, copperberyllium, copper-lead, silver-mercury, nickel-aluminum, iron-cobalt, gold-nickel, iron-silicon, and iron-aluminum are some of the $\mathrm{AB}$ type of structures (fig. 1) exhibiting such characteristics. If the previously mentioned properties of these alloys are affected by the order-disorder transformation, friction characteristics may also be influenced.

The objective of this investigation was to determine the influence of the orderdisorder transformations on the friction characteristics of metallic systems in vacuum. A single alloy system was selected, namely, the copper-gold system. This particular alloy combination was selected because it has been very thoroughly investigated in the literature (refs. 11 to 21 ) and two compound types, $A B$ and $A_{3} B$, are found in the system which exhibit the order-disorder transformation.

Friction experiments were conducted in vacuum $\left(10^{-9} \mathrm{~mm} \mathrm{Hg}\right)$ with a $3 / 16$-inchradius rider hemisphere sliding on a flat disk surface. The presence of surface oxides and contaminants, which could markedly influence friction, are appreciably reduced by conducting the experiments in vacuum. The disk specimen was the same copper-gold alloy as the rider or was 440-C stainless steel. The rider was loaded against the disk with 1000 grams, and measurements were made at sliding speeds to 880 centimeters per second.

\section{ORDER-DISORDER TRANSFORMATION}

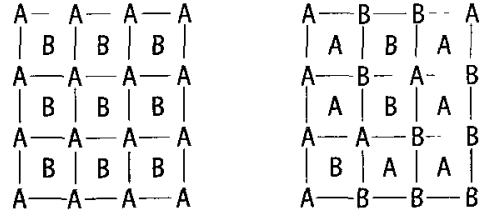

(a) Order.

(b) Disorder.

Figure 1. - Order and disorder in $A B$ alloy. Solvent, A; solute, B. (From ref. 23.)
Ordering may be defined as "a reaction or transformation in certain solid solutions in which a random arrangement of solvent and solute atoms in the crystal is replaced by a regular or ordered arrangement of the different atoms on preferred lattice sites" (ref. 22). The ordered structure of such metals and alloys is also referred to as a 
superlattice. The atomic arrangements of an ordered and a disordered structure may be seen in figure 1.

For each alloy there is some particular temperature at which a transformation from an ordered to a disordered state will take place. This temperature is, for example, $390^{\circ} \mathrm{C}$ for the alloy $\mathrm{Cu}_{3} \mathrm{Au}$ and $410^{\circ} \mathrm{C}$ for the alloy $\mathrm{CuAu}$. The critical temperature is that temperature above which the transformation marks the disappearance of long-range order over many interatomic distances. However, above the transformation temperature, some ordering among nearest neighbors may still persist, and this is called short-range ordering. Mechanical properties of alloys are markedly influenced by this change.

\section{APPARATUS AND PROCEDURE}

\section{Friction Apparatus}

The vacuum friction apparatus used in this investigation is shown in figure 2 . The basic elements of the apparatus were the specimens (a $2 \frac{1}{2}$-in. -diam. flat disk and a $3 / 16$ in. -rad. rider) mounted in a vacuum chamber. The disk specimen was driven through a magnetic-drive coupling. The coupling had two 20-pole magnets 0.150 inch apart with a 0. 030-inch diaphragm between magnet faces. The driver magnet that was outside the vacuum system was coupled to a hydraulic motor. The second magnet was completely

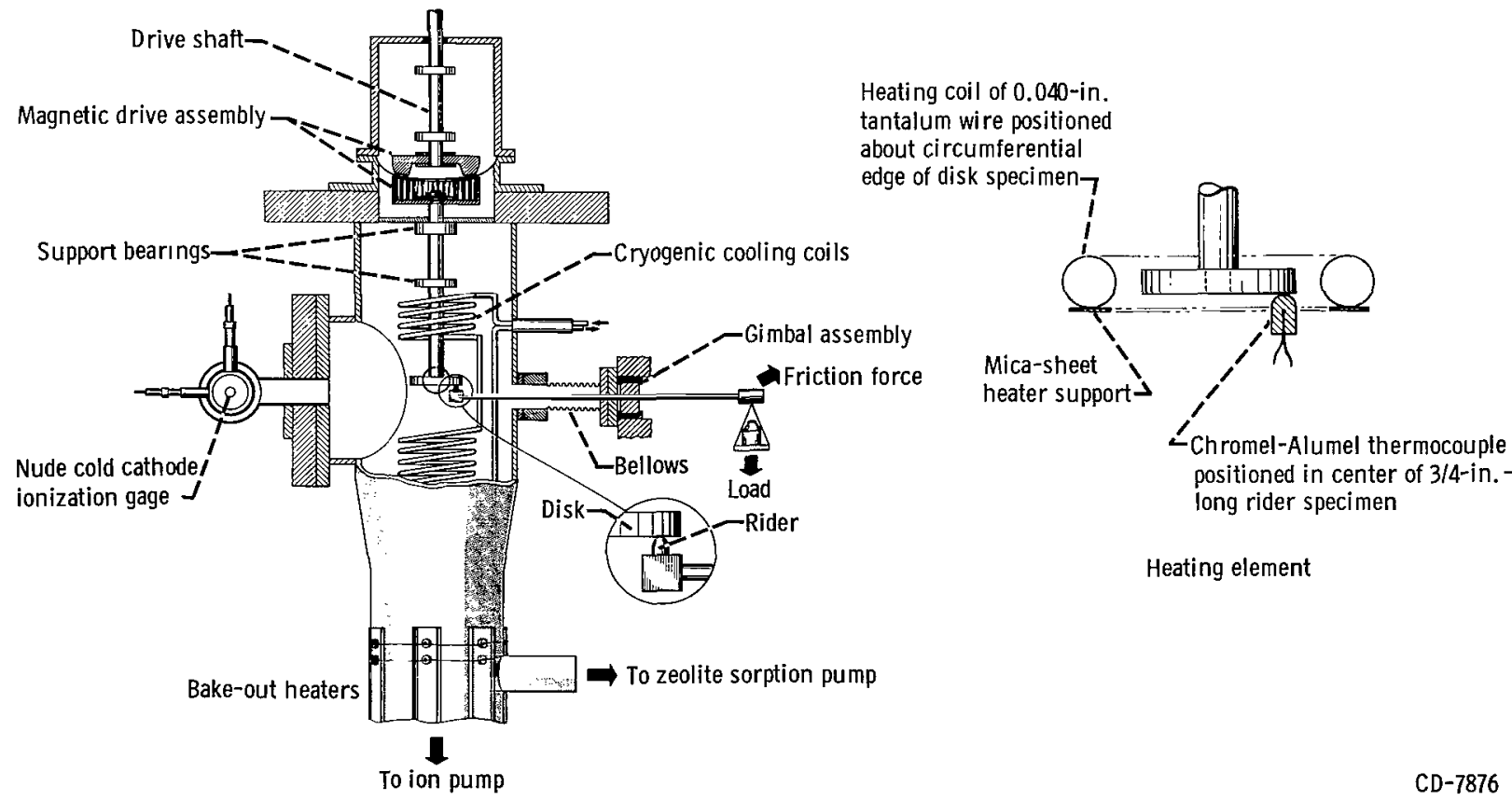

Figure 2. - High-vacuum friction and wear apparatus. 
covered with a nickel-alloy housing and was mounted on one end of the shaft within the chamber (fig. 2). The end of the shaft that was opposite the magnet contained the disk specimen.

The rider specimen was supported in the specimen chamber by an arm that was mounted by gimbals and bellows to the chamber. A linkage at the end of the retaining arm, away from the rider specimen, was connected to a strain-gage assembly. The assembly was used to measure frictional force. Load was applied through a dead-weight loading system.

Attached to the lower end of the specimen chamber were a 400-liter-per-second ionization pump and a sorption pump. The pressure in the chamber was measured adjacent to the specimen with a cold cathode ionization gage. In the same plane as the specimens and ionization gage was a diatron-type mass spectrometer (not shown in fig. 2) for determination of gases present in the vacuum system. A 20-foot-long stainless-steel coil of 5/16-inch-diameter tubing was used for liquid-nitrogen and liquid-helium cryopumping of the vacuum system.

In experiments where external heating of the specimens was required, a wire-bound tantalum heater was placed about the circumferential edge of the disk specimen (fig. 2). A thermocouple was inserted in the rider and the bulk specimen temperature was recorded after equilibrium or steady-state temperature conditions were achieved. No attempt was made to record interface temperatures.

\section{Hot-Hardness Apparatus}

A superficial Rockwell hardness tester was modified for hot-hardness measurements. The pedestal for specimen support was enclosed in a stainless-steel chamber which could be water-cooled. The specimen was placed in the chamber on the pedestal with a thermocouple welded to its surface. The thermocouple leads were brought through the stainlesssteel chamber wall. The indenter shaft was encased in a hollow sheath through which argon gas could be passed to cool and purge the chamber. The argon inlet was near the tester head, and the outlet was near the tip of the indenter attachment. The standard steel ball indentor was replaced with a sapphire ball. A rod was bellows mounted to the side of the stainless-steel chamber to facilitate specimen movement without opening the chamber to the atmosphere. A small port in the top of the stainless-steel chamber permitted the admission of the indenter. A positive pressure of argon was maintained in the chamber at all times to prevent admission of oxygen. The specimen was heated on the pedestal with an induction coil wrapped about its circumferential edge. 


\section{Alloy Preparation}

The alloys used in this investigation were prepared by induction melting of high-purity copper and gold chips in a quartz tube under vacuum. The specimens were removed from the tubes after cooling and machined into specimens for friction studies. All specimens were subsequently sealed in glass tubes under vacuum and heat treated to produce ordered and disordered structures. The $\mathrm{Cu}_{3} \mathrm{Au}$ alloys were heated in a furnace to $420^{\circ} \mathrm{C}$ and water quenched to produce the disordered state in the alloy. The ordered structure was obtained by heating the specimens for 48 hours at $350^{\circ} \mathrm{C}$. The heat treatment was adapted from reference 10 . The CuAu alloys were heated to $450^{\circ} \mathrm{C}$ and water quenched for disordering. The ordered structure was obtained by annealing at $375^{\circ} \mathrm{C}$ for 48 hours. Samples were checked by X-ray diffraction for the degree of ordering.

\section{Specimen Finish and Cleaning Procedure}

The disk and the rider specimens used in friction and wear experiments were finished to a surface roughness of 4 to 8 microinches. Before each experiment, the disk and the rider were given the same preparatory treatment:

(1) Thorough rinsing with acetone to remove oil and grease

(2) Polishing with moist levigated alumina on a soft polishing cloth

(3) Thorough rinsing with tap water followed by distilled water

For each experiment, a new set of specimens was used.

\section{RESULTS AND DISCUSSION}

The copper-gold binary alloy system possesses some interesting characteristics for

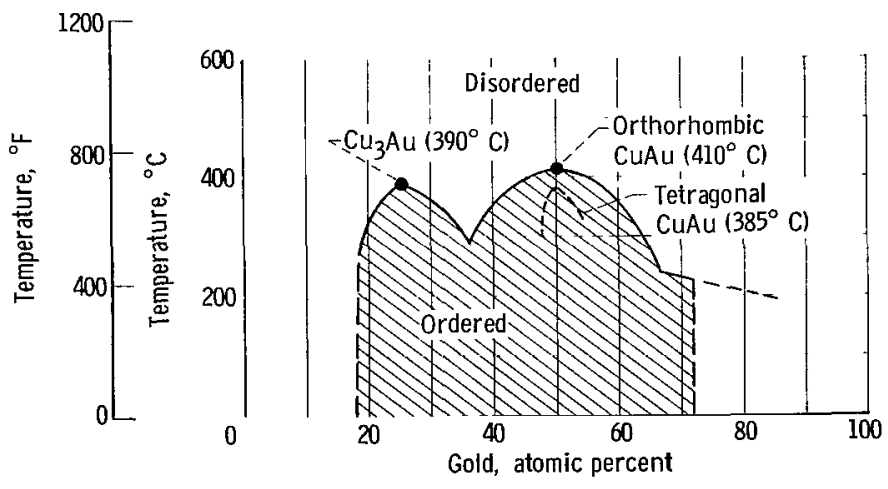

Figure 3. - Phase diagram for binary copper-gold system. (Data from ref. 23.) friction studies of order and disorder. Examination of the phase diagram for this system in figure 3 indicates a region (from 18 to approx 72 atomic percent gold) where ordering in the alloy structure may be obtained (ref. 24). From the phase diagram of figure 3, three copper-gold alloy compositions were prepared for friction experiments. One composition contained $\mathbf{1 0}$ atomic percent gold, a second 25 atomic per- 


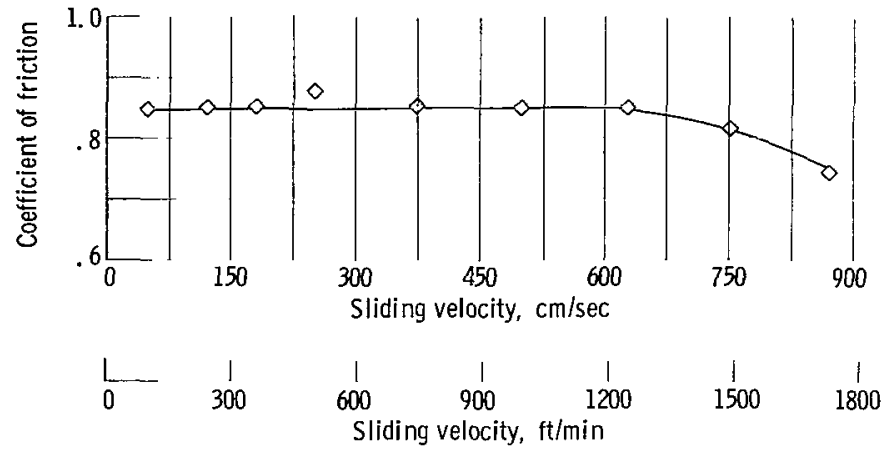

Figure 4. - Coefficient of friction at various sliding velocities for 90 -atomic-percent-copper - 10-atomic-percent-gold alloy sliding on 440-C stainless steel. Load, 1000 grams; ambient pressure, $10^{-9}$ millimeter of mercury; no external specimen heating. cent gold, and the third 50 atomic percent gold. The latter two compositions result in the compounds $\mathrm{Cu}_{3} \mathrm{Au}$ and $\mathrm{CuAu}$, respectively; in both of these compounds the structure can be ordered.

Friction experiments were conducted with the 10-atomic-percent-gold alloy. Figure 3 does not indicate any ordering for the gold-copper system in this region of the phase diagram. Friction coefficients at various sliding ve-

locities on 440-C stainless steel are presented in figure 4 for this composition. With increasing sliding velocity to 600 centimeters per second, little difference in friction was observed. At higher sliding velocities a slight decrease in friction was noted.

Friction experiments were next conducted with the copper-gold alloy $\mathrm{Cu}_{3} \mathrm{Au}$, which exhibits ordering. The alloy was examined in the ordered state. Friction results obtained at various temperatures with the alloy sliding on 440-C stainless steel are presented in figure 5. The temperatures measured were bulk and not interface temperatures. At temperatures to about $260^{\circ} \mathrm{C}$, a friction coefficient of about 0.32 was obtained. At temperatures above $260^{\circ} \mathrm{C}$, friction increased ultimately to 0.55 at $370^{\circ} \mathrm{C}$. This change in friction is believed to reflect the transformation from the ordered to the disordered state for the $\mathrm{Cu}_{3} \mathrm{Au}$ alloy. Although an examination of figure 3 indicates the transformation temperature from the ordered to the disordered state for this alloy to be $390^{\circ} \mathrm{C}$, it must be pointed out that the $260^{\circ} \mathrm{C}$ temperature indicated in figure 5 when the increase in friction begins is a bulk temperature measurement and not the interface temperature. The interface temperature was considerably higher. Data for Young's modulus from reference 11 are also included in figure 5; these data reflect the transformation from the ordered to the disordered state. Hot-hardness data were determined for the $\mathrm{Cu}_{3} \mathrm{Au}$ alloy and are also presented in figure 5 . At $365^{\circ} \mathrm{C}$ the hardness began to decrease and fell off rapidly with further increases in temperature. The adhesion characteristic of metals would reflect such changes in Young's modulus and hardness data (ref. 6) and hence friction.

It should be indicated that, with all of the copper-gold alloys of this study, a transfer film of the alloy to 440-C stainless steel occurred in the course of friction experiments. As a consequence the copper-gold alloy was sliding on a thin film of itself. In order to determine if the transformation from the ordered to the disordered state would be observed with the $\mathrm{Cu}_{3} \mathrm{Au}$ alloy sliding on a disk of the same material rather than on a thin film, a friction experiment was conducted at various sliding velocities with $\mathrm{Cu}_{3} \mathrm{Au}$ sliding 

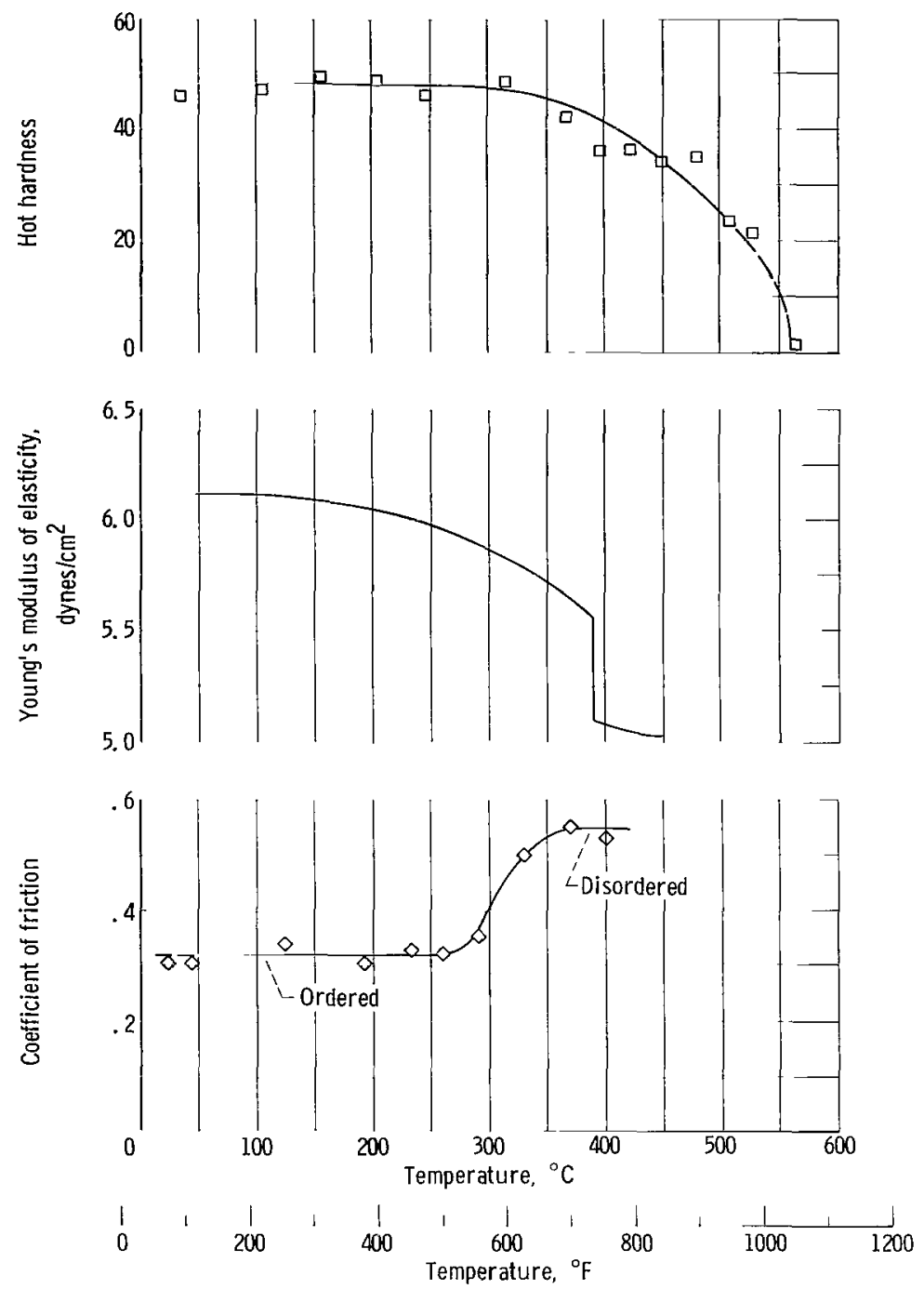

Figure 5. - Hardness, Young's modulus (from ref. 11), and coefficient of friction for $\mathrm{Cu}_{3} \mathrm{Au}$ (75 atomic percent copper -25 atomic percent gold) sliding on 440-C stainless steel at various temperatures. Load, 1000 grams; sliding velocity, 198 centimeters per second; ambient pressure, $10^{-9}$ millimeter of mercury.

on itself. The results obtained in the experiment, together with bulk rider specimen temperatures measured at the various sliding velocities, are presented in figure 6 . At sliding velocities below 250 centimeters per second the friction coefficient was 1.2. When the sliding velocity was increased from 250 to 375 centimeters per second, complete welding of the specimens occurred at the higher sliding velocity. These marked changes are again believed to reflect the influence of the order-disorder transformation of $\mathrm{Cu}_{3} \mathrm{Au}$ on friction. The maximum temperature measured was $300^{\circ}$ or $90^{\circ} \mathrm{C}$ less than the transformation temperature. It must again be pointed out that these measurements represent bulk and not interface temperatures. The considerably higher friction for 

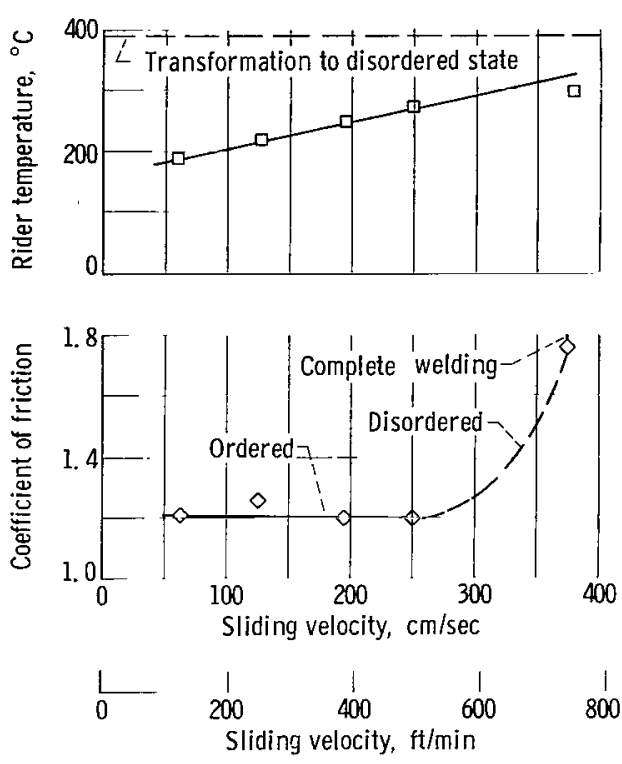

Figure 6. - Coefficient of friction for $\mathrm{Cu}_{3} \mathrm{Au}$ (75 atomic percent copper - 25 atomic percent gold) sliding on $\mathrm{Cu}_{3} \mathrm{Au}$. Ordered structure; load, 1000 grams; ambient pressure, $10^{-9}$ millimeter of mercury.
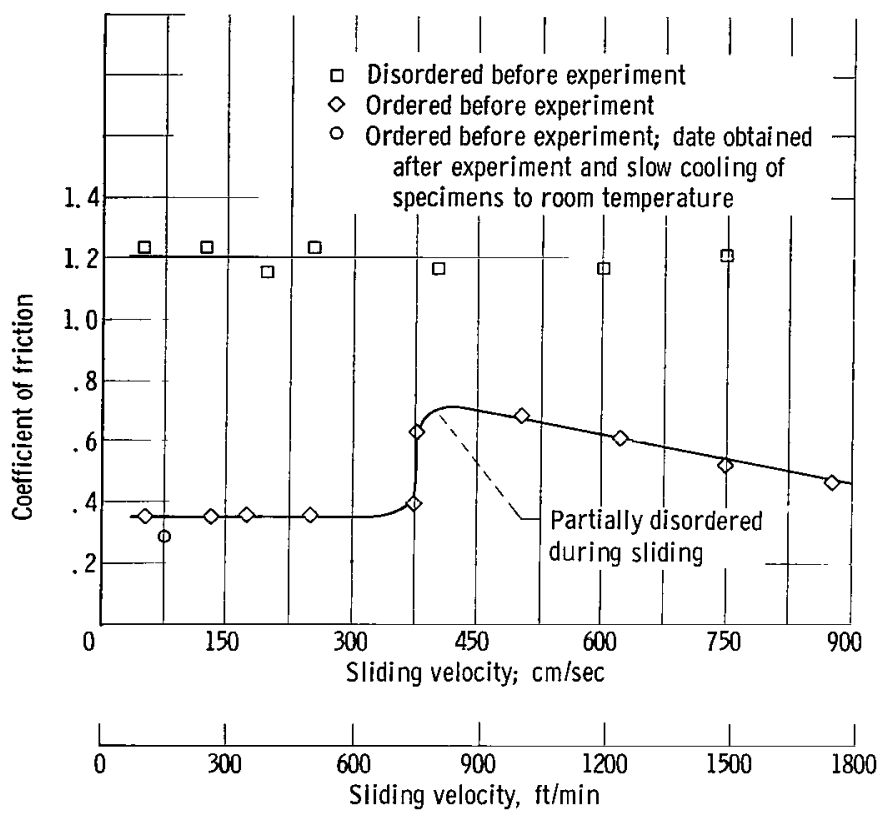

Figure 7. - Coefficient of friction for Cu Au (50 atomic percent copper 50 atomic percent gold) sliding on $440-C$ stainless steel at various velocities. Load, 1000 grams; ambient pressure; $10^{-9}$ millimeter of mercury; no external specimen heating.

$\mathrm{Cu}_{3} \mathrm{Au}$ sliding on $\mathrm{Cu}_{3} \mathrm{Au}$ than with $\mathrm{Cu}_{3} \mathrm{Au}$ sliding on $440-\mathrm{C}$ stainless steel may be related to the differences in mechanical properties of 440-C stainless steel and $\mathrm{Cu}_{3} \mathrm{Au}$. With 440-C stainless steel, the $\mathrm{Cu}_{3} \mathrm{Au}$ is sliding on a thin transfer film.

Figure 3 reveals that the copper-gold alloy $\mathrm{CuAu}$ also undergoes a transformation from the ordered to the disordered state. The transformation occurs at $410^{\circ} \mathrm{C}$. Friction experiments were conducted with the CuAu alloy sliding on 440-C stainless steel in vacuum, and the results are presented in figure 7 . With the alloy in the ordered state, a friction coefficient of 0.32 was obtained. Increase in sliding velocity (and hence interface temperature) showed a change in friction properties. At about 350 centimeters per second, a marked increase was observed. At higher sliding velocities, the friction again began to decrease. This decrease may reflect a general decrease in mechanical properties with increasing temperature. A similar effect was noted in figure 4 (p. 6) at these higher velocities. The sharp increase in friction coefficient is believed to reflect the transformation from the ordered to the disordered state for $\mathrm{CuAu}$.

In order to substantiate further the influence of ordering on $\mathrm{CuAu}$, a specimen was deliberately disordered before a friction experiment as described on page 5 . With $\mathrm{CuAu}$ in the disordered state and sliding on 440-C stainless steel, a friction coefficient of about 1.2 was obtained over the entire range of sliding velocities investigated. There were no changes such as reflected when ordering was present.

Examination of friction coefficients from the ordered to the disordered state in the transformation region (fig. 7) does not reflect an increase in friction to 1.2 , the value 

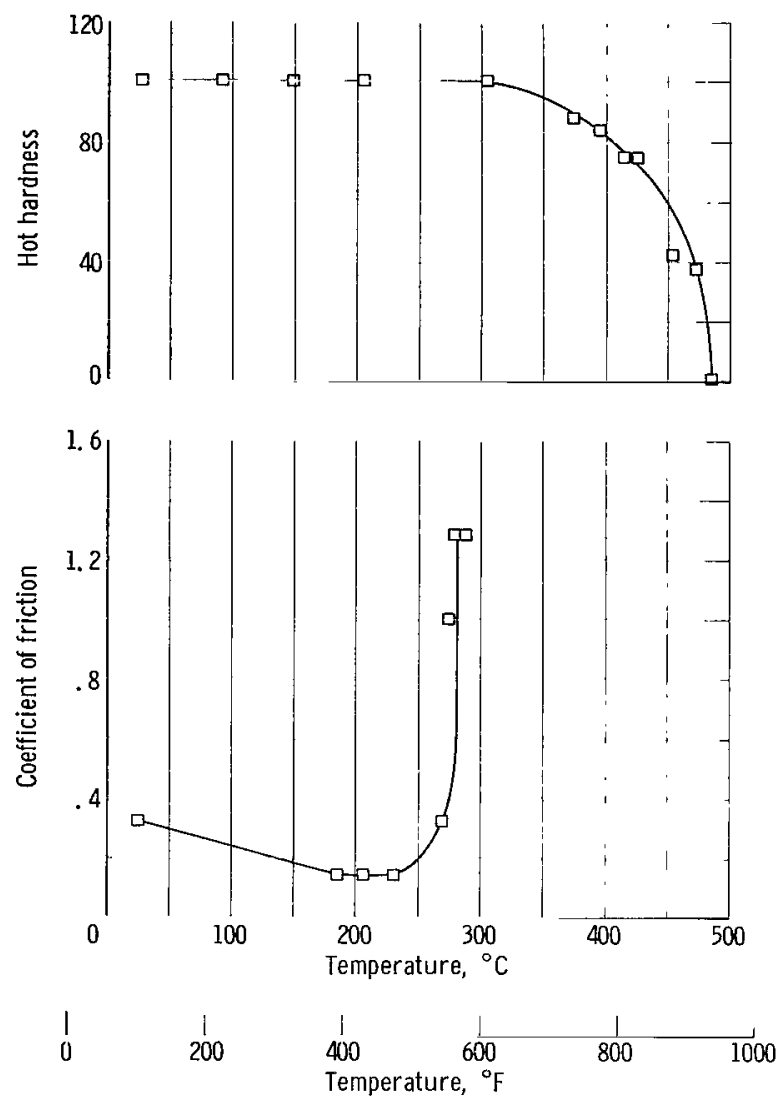

Figure 8. - Hardness and friction coefficient for CuAu (50 atomic percent copper - 50 atomic percent gold) sliding on $440-C$ stainless steel at various temperatures. Load, 1000 grams; sliding velocity, 198 centimeters per second; ambient pressure, $10^{-7}$ to $10^{-9}$ millimeter of mercury. observed when the structure was deliberately disordered before the experiment. This may be due to incomplete transformation from the ordered to the disordered state. When $\mathrm{CuAu}$ transforms from the ordered to the disordered state, long-range order is destroyed, but short-range order still persists above the transformation temperature (ref. 20). This may not be observed for $\mathrm{Cu}_{3} \mathrm{Au}$ because of an abrupt change in properties with transformation.

A friction experiment was also conducted with CuAu sliding on 440-C stainless steel in vacuum at various ambient temperatures, and the results obtained are presented in figure 8. At a constant velocity of 198 centimeters per second the friction at $20^{\circ} \mathrm{C}$ was the same as obtained in figure 6. A slight decrease in friction was observed, then a marked increase at $280^{\circ} \mathrm{C}$ to 1.27. This change in friction is again believed to reflect the transformation from the ordered to the disordered state.

Hardness data at various temperatures were also obtained for $\mathrm{CuAu}$, and the re-

sults are also presented in figure 8. In the temperature region for transformation a decrease in hardness was observed. These results are similar to those obtained with $\mathrm{Cu}_{3} \mathrm{Au}$ and indicate the influence of the order-disorder transformation on properties other than friction.

\section{SUMMARY OF RESULTS}

Friction experiments were conducted in vacuum with copper-gold alloys in order to determine the influence of ordering on the friction properties of these alloys in the absence of surface contaminants. The following results were obtained:

1. Order-disorder transformations for the copper-gold system exerted an influence on the friction coefficient of the system. A lower friction coefficient was obtained with the metal system in the ordered state than with the metal system in the disordered state. 
2. Both $\mathrm{Cu}_{3} \mathrm{Au}$ and $\mathrm{CuAu}$ exhibited an increase in friction coefficient with transformation from the ordered to the disordered state. Consistently high friction values were obtained for the 10-atomic-percent-gold alloy, which exists in the disordered state only.

Lewis Research Center,

National Aeronautics and Space Administration, Cleveland, Ohio, June 15, 1965

\section{REFERENCES}

1. Keller, Douglas V., Jr.: Adhesion Between Atomically Clear Metallic Surfaces. Rept. No. Met. E. 905-621SA, Syracuse Univ., Feb. 1, 1962.

2. Bowden, F. P.; and Tabor, D.: The Friction and Lubrication of Solids. Clarendon Press (Oxford), 1950.

3. Buckley, Donald H.; and Johnson, Robert L. : Influence of Microstructural Inclusions on Friction and Wear of Nickel and Iron in Vacuum to $10^{-9}$ Millimeter of Mercury. NASA TN D-1708, 1963.

4. Buckley, Donald H. ; Swikert, Max; and Johnson, Robert L. : Friction, Wear, and Evaporation Rates of Various Materials in Vacuum to $10^{-7} \mathrm{~mm} \mathrm{Hg.} \mathrm{ASLE} \mathrm{Trans.,}$ vol. 5, no. 1, Apr. 1962, pp. 8-22; Discussion, pp. 22-23.

5. Buckley, Donald H. ; and Johnson, Robert L. : Friction and Wear of Nickel-Aluminum Alloys and Some Sulfur-Modified Steels in Vacuum to $10^{-9}$ Millimeter of Mercury. NASA TN D-2307, 1964.

6. Sikorski, M. E.; and Courtney-Pratt, J. S. : Adhesion of Rare Earth Metals. ASLE Trans., vol. 7, no. 1, Jan. 1964, pp. 73-81.

7. Buckley, Donald H. ; and Johnson, Robert L. : Influence of Crystal Structure on Friction Characteristics of Rare-Earth and Related Metals in Vacuum to $10^{-10}$ Millimeter of Mercury. NASA TN D-2513, 1964.

8. Buckley, Donald H. ; and Johnson, Robert L. : Marked Influence of Crystal Structure on the Friction and Wear Characteristics of Cobalt and Cobalt-Base Alloys in Vacuum to $10^{-9}$ Millimeter of Mercury. I - Polycrystalline and Single Crystal Cobalt. NASA TN D-2523, 1964.

9. Buckley, Donald H.; Kuczkowski, Thomas J.; and Johnson, Robert L. : Influence of Crystal Structure on the Friction and Wear Characteristics of Titanium and Titanium Alloys in Vacuum. NASA TN D-2671, 1965. 
10. Ardley, G. W.: On the Effect of Ordering Upon the Strength of $\mathrm{Cu}_{3} \mathrm{Au}$. Acta Met. , vol. 3 , no. 6 , Nov. 1955 , pp. 525-532.

11. Westbrook, J. H., ed. : Mechanical Properties of Intermetallic Compounds. John Wiley \& Sons, Inc. , 1960.

12. Rhines, F. N.; and Newkirk, J. B.: The Order-Disorder Transformation Viewed as a Classical Phase Change. Trans. ASM, vol. 45, 1953, pp. 1029-1046; Discussion, pp. 1046-1055.

13. Glossop, Ann B. ; and Pashley, D. W. : The Direct Observation of Anti-Phase Domain Boundaries in Ordered Copper-Gold (CuAu) Alloy. Proc. Roy. Soc. (London), ser. A, vol. 250, no. 1260, Feb. 24, 1959, pp. 132-146.

14. Cohen, J. B.; and Bever, M. B.: The Effects of Cold Work on the Alloy $\mathrm{Cu}_{3} \mathrm{Au}$. Trans. AIME, vol. 218, Feb. 1960, pp. 155-165.

15. Sogie, H. J. : The Yield Strength of Partly Ordered F. C. C. Structures. Acta Met., vol. 5, no. 1, Feb. 1957, pp. 106-109.

16. Kuczynski, G. C.; Doyama, M. ; and Fine, M. E. : Transformations in Disordered Gold Copper Alloys. J. Appl. Phys., vol. 27, no. 6, June 1956, pp. 651-655.

17. Newkirk, J. B.: The Order-Disorder Transformation in Cu-Au Alloys Near the Composition $\mathrm{Cu}_{3} \mathrm{Au}$. Acta Met., vol. 2, no. 4, July 1954, pp. 644-645.

18. Wagner, W. J., Jr.; Rosenfield, A. R. ; and Averbach, B. L. : Early Stages of Plastic Flow in $\mathrm{Cu}_{3} \mathrm{Au}$. Acta Met., vol. 10, no. 3, Mar. 1962, pp. 256-257.

19. Sato, Hiroshi; and Toth, Robert S. : Long-Period Superlattices in Alloys. II. Phys. Rev., vol. 127, no. 2, July 15, 1962, pp. 469-484.

20. Oriani, R. A. : Thermodynamics of Ordering Alloys. II. The Gold-Copper System. Acta Met., vol. 2, no. 4, July 1954, pp. 608-615.

21. Rhines, F. N.; Bond, W. E.; and Rummel, R. A.: Constitution of Ordering Alloys of the System Copper-Gold. Trans. ASM, vol. 47, 1955, pp. 578-597.

22. Lyman, Taylor, ed. : Metals Handbook. ASM, 1948.

23. Kittel, C. : Elementary Solid State Physics. John Wiley \& Sons, Inc., 1962. 
$3 \mid 1818$

"The aeronautical and space activities of the United States shall be conducted so as to contribute. . . to the expansion of buman knowledge of phenomena in the atmosphere and space. The Administration shall provide for the widest practicable and appropriate dissemination of information concerning its activities and the results thereof."

-National Aeronautics and Space Act of 1958

\section{NASA SCIENTIFIC AND TECHNICAL PUBLICATIONS}

TECHNICAL REPORTS: Scientific and technical information considered important, complete, and a lasting contribution to existing knowledge.

TECHNICAL NOTES: Information less broad in scope but nevertheless of importance as a contribution to existing knowledge.

TECHNICAL MEMORANDUMS: Information receiving limited distribution because of preliminary data, security classification, or other reasons.

CONTRACTOR REPORTS: Technical information generated in connection with a NASA contract or grant and released under NASA auspices.

TECHNICAL TRANSLATIONS: Information published in a foreign language considered to merit NASA distribution in English.

TECHNICAL REPRINTS: Information derived from NASA activities and initially published in the form of journal articles.

SPECIAL PUBLICATIONS: Information derived from or of value to NASA activities but not necessarily reporting the results of individual NASA-programmed scientific efforts. Publications include conference proceedings, monographs, data compilations, handbooks, sourcebooks, and special bibliographies.

Details on the availability of these publications may be obtained from:

SCIENTIFIC AND TECHNICAL INFORMATION DIVISION

NATIONAL AERONAUTICS AND SPACE ADMINISTRATION

Washington, D.C. 20546 